\title{
Maximum shear modulus of calcareous sand in Dejebel Dahar, Tunisia and its dependency on applied stress
}

\author{
Hyunwook Choo ${ }^{1, *}$, Minhyuk Kwon ${ }^{1}$, Lamia Touiti ${ }^{2}$, and Young-Hoon Jung ${ }^{1}$ \\ ${ }^{1}$ Kyung Hee University, Department of Civil Engineering, 17104 Yongin, South Korea \\ ${ }^{2}$ University of Gabès, Civil Engineering Laboratory, 6029 Tunis, Tunisia
}

\begin{abstract}
The present experimental investigation aims at investigating the small strain stiffness of calcareous sand as a function of applied stress. The calcareous sand was sampled at Tunisia's Dejebel Dahar region, and the shear wave velocity $\left(V_{s}\right)$ of calcareous sand was measured using modified oedometer cell equipped with bender elements. The results of this study demonstrate that the $V_{s}$ of the tested calcareous sand is smaller than that of silica sand with minimal crushable particles at relatively low applied stress $(\sigma)$; however, $V_{s}$ of calcareous sand is greater than that of silica sand at high $\sigma$, reflecting strong dependency of calcareous sand on $\sigma$. The applied stress dependency of soils can be expressed as a power function of applied stress $\left(V_{s}=\alpha(\sigma\right.$ $/ 1 \mathrm{kPa})^{\beta}$, where $\alpha=V_{s}$ at $\sigma=1 \mathrm{kPa}$ and $\beta=$ stress exponent). Generally, the single $\alpha-\beta$ can capture the dependency of $V_{s}$ on $\sigma$, and the typical $\beta$ value for sand is around 0.25 . The measured $\beta$ of tested silica sand was around 0.20; while, Tunisia calcareous sand shows $\beta$ of greater than 0.32 , and the dependency of $V_{s}$ on $\sigma$ cannot be captured by single $\alpha-\beta$. This can be attributed to the fact that the variation of $V_{s}$ of tested calcareous sand with increasing $\sigma$ reflects not only fabric change but also particle crushing.
\end{abstract}

\section{Introduction}

The calcareous sand is very common in many arid and semiarid regions. Calcareous sand is composed of relatively easy breakable particles such as shell, hollow coral, and others. In addition, the main mineral of calcareous sand is $\mathrm{CaO}$. Therefore, the physical and mechanical properties of calcareous sand are significantly deviated from those of silica sand [1]. To use calcareous sand in geotechnical projects, the characterization of engineering properties of calcareous sand is very important; therefore, many researchers have evaluated the compressibility and large strain shear strength (or friction angle) of calcareous sands [1-3]. However, studies focusing on the small strain stiffness of calcareous sand have been very limited. Note that the small strain stiffness or shear wave velocity gives insight into the deformation characteristics of soils; thus, it is an important input parameter in the design and analysis of soils and soilstructure interactions. Consequently, the present experimental investigation aims at investigating the small strain stiffness of calcareous sand as a function of applied stress.

\section{Experimental program}

Two sands, which are Tunisia calcareous sand and Jumunjin sand were used in this study. Jumunjin sand is the Korea standard silica sand (Table 1), and Tunisia sand is the calcareous sand which was sampled near the lake of Tunis, Tunisia. Due to the marine transgression, calcareous sand with high content of $\mathrm{CaO}$ can be found in this area (Table 1 and Figure 1). In addition, due to the large amount of organic materials such as shell and coral, the measured LOI (loss on ignition) was greater than 44 $\%$ (Table 1). The basic index properties, including specific gravity, median particle size, uniformity coefficient, maximum void ratio, and minimum void ratio, are shown in Table 2. According to unified soil classification system, Tunisia sand and Jumunjin sand can be classified as well-graded sand and poorly-graded sand, respectively. To measure both shear wave velocity and compressibility, sand specimens with height of and diameter of at initial relative density $\sim 30 \%$ in oedometer cell.

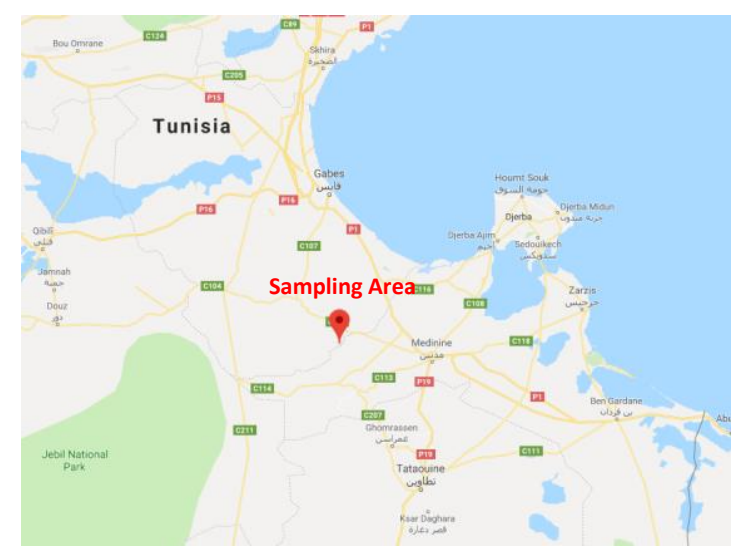

Fig. 1. Sampling location of Tunisia calcareous sand.

\footnotetext{
"Corresponding author: choohw@khu.ac.kr
} 
Table 1. Chemical composition.

\begin{tabular}{|c|c|c|c|c|c|}
\hline Type & $\mathrm{SiO}_{2}$ & $\mathrm{Al}_{2} \mathrm{O}_{3}$ & $\mathrm{CaO}$ & $\mathrm{K}_{2} \mathrm{O}$ & LOI \\
\hline $\begin{array}{c}\text { Tunisia } \\
\text { sand }\end{array}$ & 2.62 & 0.04 & 44.79 & 0.03 & 44.42 \\
\hline $\begin{array}{c}\text { Jumunjin } \\
\text { sand }\end{array}$ & 89.21 & 5.11 & 0.1 & 4.06 & 0.38 \\
\hline
\end{tabular}

Table 2. Material properties.

\begin{tabular}{|c|c|c|c|c|c|}
\hline Type & $G_{s}$ & $\begin{array}{c}D_{50} \\
(\mathrm{~mm})\end{array}$ & $C_{u}$ & $e_{\max }$ & $e_{\min }$ \\
\hline $\begin{array}{c}\text { Tunisia } \\
\text { sand }\end{array}$ & 2.75 & 1.00 & 12.0 & 0.77 & 0.44 \\
\hline $\begin{array}{c}\text { Jumunjin } \\
\text { sand }\end{array}$ & 2.62 & 0.43 & 1.47 & 0.93 & 0.65 \\
\hline
\end{tabular}

Note: $G_{s}=$ specific gravity; $D_{50}=$ median particle size; $C_{u}=$ uniformity coefficient; $e_{\max }$ and $e_{\min }=$ maximum and minimum void ratios, respectively

The shear wave velocity $\left(V_{s}\right)$ of two sands (Tunisia and Jumunjin) was measured using bender elements fitted inside a modified oedometer cell, which allowed measurement of the shear wave velocity as a function of increasing vertical effective stress. The tests were carried out at a constant displacement rate of $0.02 \mathrm{~mm} / \mathrm{min}$. The shear waves were meausred continuously under vertical stresses ranging from $20 \mathrm{kPa}$ to $12,300 \mathrm{kPa}$. The shear wave, which traveled through the soil specimen, was generated by a function generator (33210A, Agilent), with a square wave of frequency $=20 \mathrm{~Hz}$ and amplitude $=10$ $\mathrm{V}$, which was connected to the source bender element. The bender element that acted as the signal receiver was connected to a filter amplifier (3364, Krohn-Hite), which in turn was connected to a digital oscilloscope (DSO5014A, Agilent). A total of 1024 signals were stacked to reduce the influence of uncorrelated noise. Travel time of the shear wave was determined using the digitized signal, as recorded by the oscilloscope [4], and the tip-to-tip distance (the distance from the tip of the source bender to the tip of the receiver bender element) was used as the travel distance.

\section{Results and discussion}

\subsection{Compressibility of tested materials}

In the case of soils with negligible particle crushing, the compressibility is the measure of volume change due to the particle rearrangement. In contrast, for the soils containing considerable amount of crushable particles, the compressibility is the result of volume change due to both particle rearrangement and particle crushing. Thus, crushable soils such as calcareous sand can show greater compressibility (or compression index) than silica sand with minimum particle crushing. Figure 2 shows the variation of void ratio of both Tunisia and Jumunjin sands at initial relative density of around $30 \%$ as a function of vertical effective stress. Because Tunisia sand is wellgraded sand with $C_{u} \sim 12$, the initial void ratio of Tunisia sand is smaller than that of Jumunjin sand. Thus, it is expected that the compressibility of Tunisia sand is smaller than that of Jumunjin sand. However, Figure 1 reveals that the change in void ratio (or compressibility) of Tunisia sand is greater than that of Jumujin sand. To highlight the different compressibility of two tested sands, the normalized compressibility, which was defined as the ratio between void ratio and void ratio at vertical effective stress $\sim 5 \mathrm{kPa}$, is plotted in Figure 3. Figure 3 clearly demonstrates that Tunisia sand shows greater compressibility than Jumunjin sand. This observation reflects that the volume change of Tunisia sand according to applied stress is the result of not only particle rearrangement, but also particle crushing.

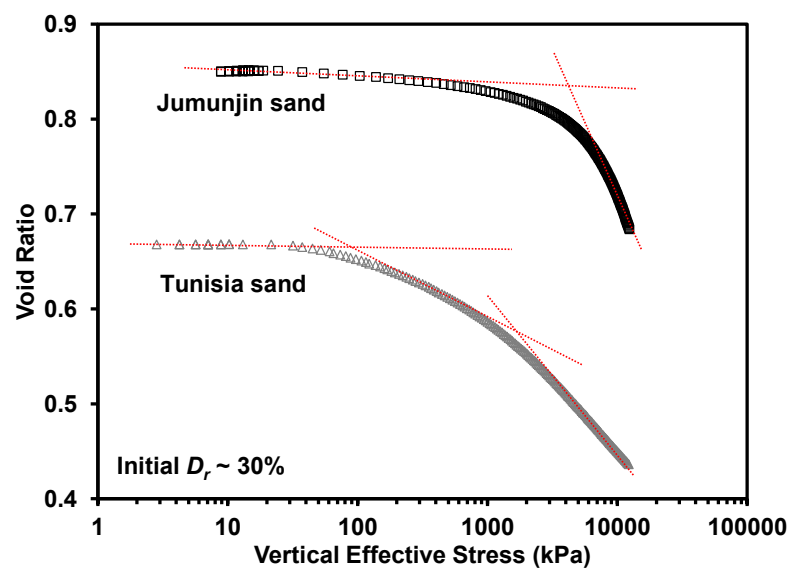

Fig. 2. Variation of void ratio according to vertical effective stress.

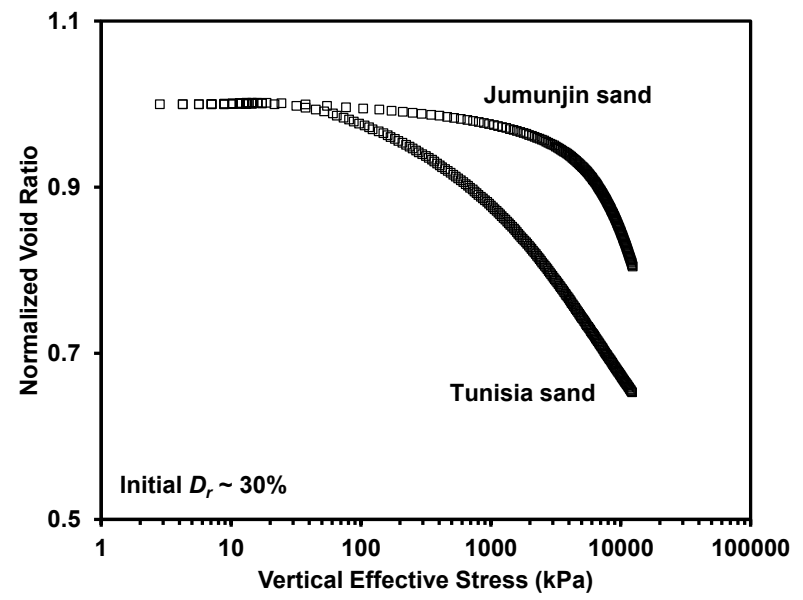

Fig. 3. Variation of normalized void ratio according to vertical effective stress (normalized void ratio $=$ void ratio $/$ void ratio at vertical effective stress $=5 \mathrm{kPa}$ ).

Figure 2 also demonstrates that the yield stress, which can be defined as the vertical stress with the initiation of significant volume change, of Jumunjin sand is around 5 MPa. Note that this yield stress may indicate the stress at which the significant breakage of particles initiates. In contrast, Tunisia sand shows the change of slope between the void ratio and vertical stress at around $300 \mathrm{kPa}$, reflecting that Tunisia calcareous sand starts to break at relative low applied stress. In addition, the significant change in slope between void ratio and stress can be observed at around $2 \mathrm{MPa}$. Note that the Tunisia sand show very high LOI values, reflecting high content of organic materials. Because the organic materials such as 
shell and hollow coral can be easily broken at relatively low applied stress, the first deflection point may indicate the initiation of breakage of organic materials. Additionally, because the mineral stiffness of $\mathrm{CaO}$ is smaller than that of silica, the second deflection point, which may indicate the initiation of significant particle crushing, is smaller than the yield stress of Jumunjin sand.

\subsection{Maximum shear modulus of tested materials}

Figure 4 shows the measured shear wave velocity of both Tunisia and Jumunjin sand at initial relative density of around $30 \%$ as a function of vertical effective stress. Generally, the stiffness or shear wave velocity of soils is determined by the nature of both the interparticle contacts and the interparticle coordination number [5]. Because the increase in applied stress implies an increase in contact area and a decrease in void ratio (or porosity) implies an increase in interparticle coordination, the shear wave velocity increases with an increase in applied stress (Figure 4). Additionally, because the void ratio of Tunisia sand is much smaller than Jumunjin sand at a given applied stress as shown in Figure 2, the shear wave velocity of Tunisia sand is expected to be greater than that of Jumunjin sand. However, the measured shear wave velocity of Jumunjin sand is greater than that of Tunisia sand at relatively low applied stress $(<300 \mathrm{kPa})$ and vice versa at high applied stress $(>300 \mathrm{kPa})$ (Figures 4 and 5$)$. The particle size of organic materials such as shell and corals is generally greater than the mineral sand particles. Therefore, at low applied stress, the applied stress may be transferred through the contacts between organic particles because mineral sand particles will be retained in the pore space between organic particles. Thus, the interparticle contact stiffness between organic particles will determine the shear wave velocity or maximum shear modulus of tested calcareous sand at low stress level. Consequently, at low stress level, the shear wave velocity of Jumunjin sand can be greater than that of Tunisia sand though Tunisia sand has much greater interparticle coordination.

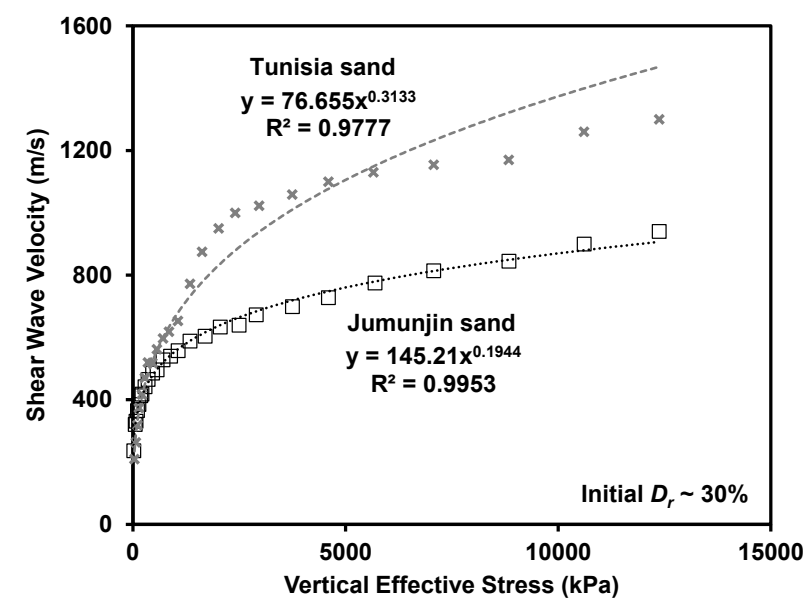

Fig. 4. Variation of shear wave velocity according to vertical effective stress.

As already shown in Figure 2, the tested Tunisia sand starts to break at vertical effective stress of around 300 $\mathrm{kPa}$. Because the first deflection in the relationship between void ratio and applied stress in Figure 2 is the result of breakage of organic particles, the direct contact between mineral sand particles can be developed with increasing applied stress. Therefore, the cross-over point can be found between shear wave velocity of Jumunjin and Tunisia sands at vertical stress of around 200-300 kPa, which is the very similar stress level for the first deflection point in Figure 2.

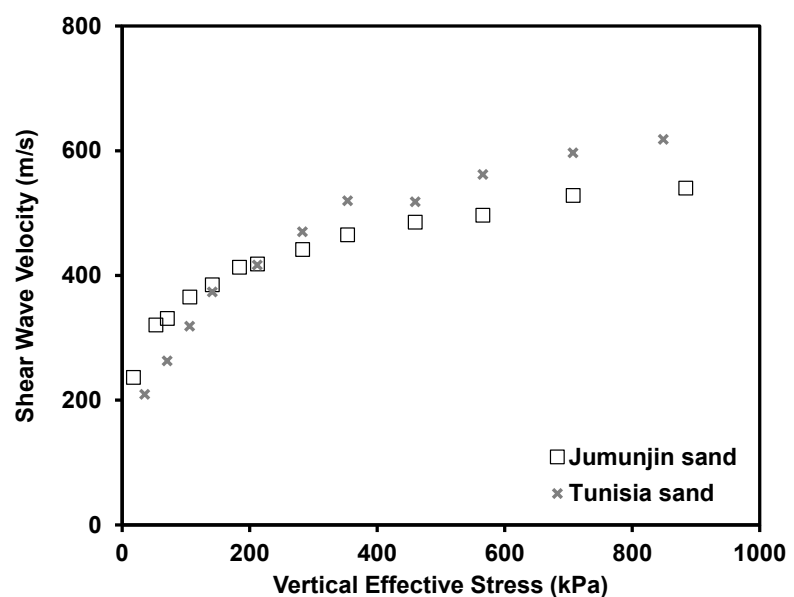

Fig. 5. Comparison of shear wave velocities of two sands at low applied stress.

The applied stress dependency of soils can be expressed as a power function of applied stress $\left(V_{s}=\alpha(\sigma\right.$ $/ 1 \mathrm{kPa})^{\beta}$, where $\alpha=V_{s}$ at $\sigma=1 \mathrm{kPa}$ and $\beta=$ stress exponent). Generally, the single $\alpha-\beta$ can capture the dependency of $V_{s}$ on $\sigma$, and the typical $\beta$ value for sand is around 0.25 . Figure 4 demonstrates that the measured shear wave velocity of Jumunjin sand can be expressed as the single $\alpha-\beta$, and the measured $\beta$ is around 0.20 . In contrast, the variation of shear wave velocity of Tunisia sand according to applied stress cannot be captured by single $\alpha-\beta$ because of the significant particle crushing. Because $\beta$ is very sensitive to the change in contact mode that constitutes structural skeleton [6], the measured shear wave velocity of Tunisia sand was divided into 4 different zones in Figure 6.

Figure 6 demonstrates that the zone I (vertical effective stress $<1 \mathrm{MPa}$ ) shows $\beta$ of around 0.34 . In zone II $(1 \mathrm{MPa}<$ vertical stress $<2.5 \mathrm{MPa}), \beta$ is very high $(0.52)$ indicating that the dominant interparticle contact mode is shifted from the organic particles-organic particles or organic particles-mineral sand particles to mineral sand particles-mineral sand particles. Because the interparticle contact stiffness between mineral sand particles is much greater than that between organic particles, a rapid increase in shear wave velocity can be observed in zone II. In zone III (2.5 MPa $<$ vertical stress $<8 \mathrm{MPa})$, the measured $\beta$ value is very small $(0.13)$, reflecting insignificant effect of applied stress on shear wave velocity. As shown in Figure 2, the applied stress at which the significant change in slope between void ratio and stress occurs is around $2 \mathrm{MPa}$. Through the Zone II, the contact between mineral sand particles has been the structural skeleton. However, at high stress level (2 MPa), the mineral sand particle can be broken because of relatively low mineral strength of $\mathrm{CaO}$. Therefore, in 
Zone III, there could be an offset mechanism between an increase in interparticle coordination and a decrease in interparitcle contact stiffness with increasing applied stress. Consequently, in Zone III, the effect of applied stress on an increase in shear wave velocity can be insignificant. In Zone IV, the measured $\beta$ is around 0.32 , which means the moderate dependency of the measured shear wave velocity on applied stress. This in turn reflects that the significant particle crushing has been finished, leading to the increase contact area and denser formation of crushed particles with increasing applied stress.

Finally, it is notable that stiffer materials will have greater $\alpha$ but smaller $\beta$, and the $\alpha$ and $\beta$ are inversely proportional. Generally, soils will smaller void ratio (or porosity) shows greater stiffness, leading to greater $\alpha$ but smaller $\beta$. However, Jumunjin sand, which has greater void ratio than Tunisia sand, shows greater $\alpha$ but smaller $\beta$ than Tunisia sand (Figure 4).

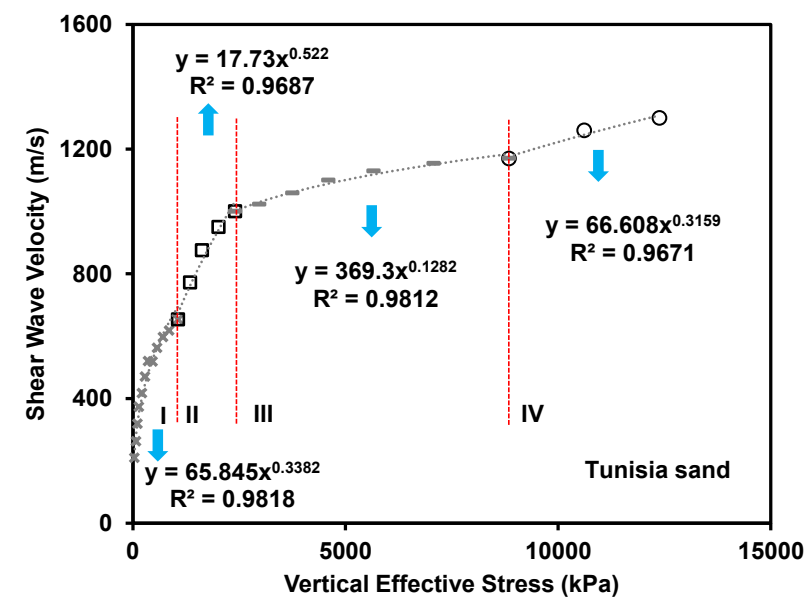

Fig. 6. Change in contact behavior of tested Tunisia calcareous sand according to vertical effective stress.

\section{Conclusion}

The shear wave velocity $\left(V_{s}\right)$ of tested calcareous sand is smaller than that of silica sand with minimal crushable particles at relatively low applied stress $(\sigma)$; however, $V_{s}$ of calcareous sand is greater than that of silica sand at high $\sigma$, reflecting strong dependency of calcareous sand on $\sigma$. The applied stress dependency of soils can be expressed as a power function of applied stress $\left(V_{s}=\alpha(\sigma / 1 \mathrm{kPa})^{\beta}\right.$, where $\alpha=V_{s}$ at $\sigma=1 \mathrm{kPa}$ and $\beta=$ stress exponent). Generally, the single $\alpha-\beta$ can capture the dependency of $V_{s}$ on $\sigma$, and the typical $\beta$ value for sand is around 0.25 . The measured $\beta$ of tested silica sand was around 0.20 ; while, Tunisia calcareous sand shows $\beta$ of greater than 0.32 , and the dependency of $V_{s}$ on $\sigma$ cannot be captured by single $\alpha-\beta$. This can be attributed to the fact that the variation of $V_{s}$ of tested calcareous sand with increasing $\sigma$ reflects not only fabric change but also particle crushing.

\section{References}

1. X. Z. Wang, Y. Y. Jiao, R. Wang, M.J. Hu, Q. S. Meng, F. Y. Tan, Eng. Geol., 120, 1-4, 40-47 (2011)
2. H. Shahnazari, R. Rezvani, Eng. Geol., 159, 98-105 (2013)

3. H. Shahnazari, H. Salehzadeh, R. Rezvani, Y. Dehnavi, KSCE J. of Civ. Eng., 18, 4, 975-983 (2014)

4. H. Choo, S. Burns, Gran. Matt., 17, 5, 567-578 (2015)

5. H. Choo, S. Burns, Soil Dyn. and Earthq. Eng., 60, 44-50 (2014) 